\title{
Los asentamientos Ticuna de hoy en la ribera del río Amazonas colombiano
}

\author{
Elizabeth Riaño Umbarila*
}

Resumen. Este artículo describe la configuración actual de los asentamientos de población Ticuna en la ribera del río Amazonas colombiano. Un asentamiento Ticuna, esta conformado por dos sectores claramente establecidos, el primero corresponde a la cabecera, lugar donde se localizan las viviendas y las pequeñas infraestructuras estatales y el segundo corresponde al entorno de esta, donde se localizan las chagras o zonas de cultivo y los sitios de pesca, caza y recolección. La manera en que estos grupos han conformado sus asentamientos corresponde a las estructuras económica, social y político administrativa que han desarrollado en respuesta a sus necesidades como grupo étnico, en contacto permanente con la otra cultura. Palabras clave: Ticuna, asentamiento, cabecera, chagra, várzea, tierra firme, vivienda.

\footnotetext{
* Arquitecta, Universidad Nacional de Colombia, Bogotá. Magíster en Geografía, énfasis en Ordenamiento Territorial, EPG, Convenio UPTC-IGAC, Bogotá.
} 


\section{Introducción}

El patrón de asentamiento tradicional de los Ticuna y de los demás grupos habitantes de la ribera del Amazonas, se ha transformado desde los siglos XVII y XVIII, cuando se dio inicio a un proceso de delimitación urbana, que se evidenció en la creación de aldeas o poblados; esta forma de organizar el espacio fue impulsada como estrategia de ocupación por parte de colonizadores y misioneros que las convirtieron en centro de control y reducción a la vida civilizada, permitiéndoles concentrar mano de obra cautiva y mantener el poder administrativo y político. Muchos de aquellos caseríos desaparecieron y otros poblados fueron fundados en varias ocasiones.

Entrado el siglo XX, los Ticuna, habitantes mayoritarios de la ribera del río Amazonas, en el sector colombiano, vivían en forma dispersa. Es decir, no conformaban caseríos o agrupaciones de tipo urbano. Esto se inició a partir de los años sesenta mediante un proceso de nucleación de los grupos indígenas, como una estrategia del Estado y la iglesia para facilitar la evangelización, la prestación de servicios de salud, educación y la dotación de infraestructuras.

Desde entonces se han dado transformaciones que se relacionan con la cercanía al río Amazonas y a los centros de acopio y consumo, esta forma de poblamiento ha significado profundas cambios en las estructuras económica, política, social y cultural de los grupos que allí habitan.

\section{Localización}

Los Ticuna se distribuyen en la zona de frontera de Colombia, Perú y Brasil, a lo largo del río Amazonas, en una extensión de $900 \mathrm{Km}$., comprendidos entre la desembocadura del río Atacuari en Colombia, hasta la desembocadura del río Coarí en Brasil. Véase el mapa No. 1.

En Colombia, se localizan en los municipios de Leticia y Puerto Nariño y en el corregimiento de Tarapacá; en el Perú en el departamento de Loreto, en la provincia de Mainas, en los distritos Ramón Castilla y Yavarí; en Brasil en los municipios de Tabatinga, Benjamín Constant, Säo Paulo de Olivença, Tefé, Santo Antonio do Içá, Jutaí, Anamä, Beruri, Amaturá, Tonantins, Uarini y Alvaräes.

La población Ticuna en el Perú se estimó para el año 1993 en 1.787 personas (GEF/ PNUD, UNOPS, 1997). Para Brasil se contaban 25.737 personas en 1998 (FINEP/PPG-7 CGTT, 1998).

\subsection{Los Ticuna colombianos}

Los Ticuna constituyen el grupo étnico más numeroso del Trapecio Amazónico Colombiano. En la zona urbana del municipio de Leticia, se ubican familias de población Ticuna habitando de manera dispersa en los distintos barrios de la ciudad y en forma concentrada en el sector de la carretera Leticia-Tarapacá y junto a la vía que conduce a los Lagos de Yahuarcaca. En la zona rural los

8 Elizabeth Riaño Umbarila 
encontramos sobre la ribera de los ríos Amazonas, Amacayacú, en otros afluentes menores y en los lagos de Yahuarcaca.

En el casco urbano del municipio de Puerto Nariño se halla una población numerosa y concentrada; en la zona rural del mismo, sobre los ríos Amazonas, Loretoyacú, Atacuari y caño Boiauassú hay también familias Ticuna.

Al norte del Trapecio Amazónico se encuentran en el área urbana del corregimiento de Tarapacá y sobre el río Cotuhé en las comunidades de Caño Ventura, Santa Lucía y Buenos Aires; sobre el río Putumayo los encontramos en Puerto Nuevo y en Puerto Ticuna.

\subsubsection{Los Ticuna en la ribera del río Amazonas colombiano}

De acuerdo con el censo efectuado por ACITAM $^{1}$ y esta investigación, donde se excluye la población residente en el casco urbano de Leticia, el número de habitantes Ticuna en la ribera del río Amazonas colombiano era de 7.890 , hasta diciembre de 2000 , lo que equivale al $59,33 \%$ de la población residente en la ribera del río Amazonas colombiano, que hizo parte del censo.

Junto a los Ticuna existen otros grupos étnicos, entre los cuales se destacan los Cocama y los Yagua. La población Cocama representa el 19.93\% seguida de la Yagua con el $6.87 \%$. Otros grupos suman el 3.39\% y la población mestiza el 9.38\%. Los colonos representan el 1.11\%.

Véase la Tabla No. 1.

Tabla No. 1

Población residente en la ribera del Amazonas por grupo étnico

\begin{tabular}{|c|c|c|c|c|c|c|c|c|}
\hline \multirow{2}{*}{$\begin{array}{c}\text { TOTAL } \\
\text { POBLACIÓN }\end{array}$} & TICUNA & COCAMA & YAGUA & UITOTO & BORA & MESTIZO & COLONO & $\begin{array}{c}\text { OTROS } \\
\text { GRUPOS } \\
\text { ÉTNICOS }\end{array}$ \\
\hline 13.298 & 7.890 & 2.650 & 913 & 320 & 36 & 1247 & 148 & 94 \\
\hline $100 \%$ & $59,33 \%$ & $19,93 \%$ & $6,87 \%$ & $2,41 \%$ & $0,27 \%$ & $9,38 \%$ & $1,11 \%$ & $0,71 \%$ \\
\hline
\end{tabular}

Fuente: Censo elaborado por ACITAM y datos tomados durante trabajo de campo.

En el Mapa No. 2. y en las Tablas No. 2. y No. 3, se presentan los caseríos, los grupos étnicos predominantes y los minoritarios en cada aldea. La población Ticuna es mayoritaria en casi todos los asentamientos donde se les ubica, pero cada vez son menos aquellos de carácter monoétnico. Los principales centros de población Ticuna continúan siendo Arara y Nazareth.

$\overline{1}$ Asociación de Cabildos Indígenas del Trapecio Amazónico. 
Tabla No. 2.

Caseríos y grupos étnicos predominantes en la ribera del Amazonas, municipio de Leticia

\begin{tabular}{|c|c|c|c|}
\hline \multicolumn{4}{|c|}{ MUNICIPIODELETICIA } \\
\hline No. & COMUNIDAD & $\begin{array}{l}\text { GRUPO ÉTNICO } \\
\text { PREDOMINANTE }\end{array}$ & OTROS GRUPOS EN LA ALDEA \\
\hline \multicolumn{4}{|c|}{ CARRETERA LETICIA-TARAPACÁ } \\
\hline 1 & Km. 3 San Miguel & UITOTO & Ticuna, Cocama, mestizo \\
\hline 2 & Km. 6 San José & TICUNA & Cocama. Uitoto, colono \\
\hline 3 & Km. 7 & UITOTO & Ticuna \\
\hline 4 & Km. 9.5 Monilla Mena & UITOTO & Mestizo, Colono \\
\hline 5 & Km. 11 & UITOTO & Mestizo, otros, Yaguas, Cocamas, Ticunas \\
\hline 6 & Km. 11 Multiétnico & MESTIZO & Yagua \\
\hline 7 & Km. 18 Pichuna & COLONOS & Mestizos \\
\hline \multicolumn{4}{|c|}{ LOS LAGOS } \\
\hline 8 & San Pedro de los Lagos & TICUNA & Cocama \\
\hline 9 & San Antonio Lagos & TICUNA & Cocama, Yagua \\
\hline & San Sebastián & TICUNA & Cocama, Yagua \\
\hline 11 & San Juan de Los Parentes & TICUNA & Cocama \\
\hline 12 & Castañal & TICUNA & Cocama, otros, mestizos \\
\hline \multicolumn{4}{|c|}{ RÍO AMAZONAS } \\
\hline & La Playa & COCAMA & Ticuna \\
\hline & La Milagrosa & COCAMA & Ticuna, mestizos \\
\hline 15 & Ronda & COCAMA & Ticuna, Yagua \\
\hline 16 & La Beatriz & COCAMA & Ticuna, Yagua \\
\hline 17 & San José del Río & COCAMA & Mestizo \\
\hline 18 & Nazareth & TICUNA & Cocama \\
\hline 19 & Arara & TICUNA & Yagua \\
\hline & Los Yaguas & YAGUA & Mestizos, Cocamas, otros, Ticunas \\
\hline & El Progreso & TICUNA & Yagua \\
\hline 22 & Santa Sofía & TICUNA & Cocama, mestizo, otros \\
\hline 23 & Nuevo Jardín & TICUNA & \\
\hline 24 & Loma Linda & TICUNA & Cocama, mestizo, \\
\hline 25 & El Paraná & COCAMA & Mestizo \\
\hline & Puerto Triunfo & TICUNA & Cocama, Yagua, otros (Bora) \\
\hline 27 & La Libertad & YAGUA & \\
\hline 28 & Zaragoza & TICUNA & Yagua, Cocama, Uitoto \\
\hline 29 & El Vergel & TICUNA & Cocama, Yagua, mestizo, \\
\hline & Macedonia & TICUNA & Cocama, Yagua, Uitoto, mestizo \\
\hline & Mocagua & TICUNA & Cocama, Yagua, Uitoto \\
\hline & Palmeras & TICUNA & Cocama, Yagua \\
\hline \multicolumn{4}{|c|}{ RÍO AMACAYACÚ } \\
\hline & San Martín de Amacayacú & TICUNA & Uitoto \\
\hline
\end{tabular}

Fuente: datos recogidos por la autora durante trabajo de campo.

10 Elizabeth Riaño Umbarila 
Tabla No. 3

Caseríos y grupos étnicos predominantes en la ribera del Amazonas, municipio de Puerto Nariño

\begin{tabular}{|c|c|c|c|}
\hline \multicolumn{4}{|c|}{ MUNICIPIO DE PUERTO NARIÑO } \\
\hline No. & COMUNIDAD & $\begin{array}{l}\text { GRUPO ÉTNICO } \\
\text { PREDOMINANTE }\end{array}$ & OTROS GRUPOS EN LA ALDEA \\
\hline RÍO & \multicolumn{3}{|l|}{ AMAZONAS } \\
\hline 1 & Valencia & COCAMA & Ticuna, Yagua \\
\hline 2 & Puerto Esperanza & TICUNA & Uitoto \\
\hline 3 & Veinte de Julio & YAGUA & Ticuna \\
\hline 4 & Patrulleros & TICUNA & Cocama \\
\hline 5 & Puerto Nariño & TICUNA & Mestizo, Cocama, colono, Yagua, otros \\
\hline 6 & Pozo Redondo & TICUNA & \\
\hline 7 & Naranjales & TICUNA & Cocama, Yagua, Uitoto \\
\hline 9 & Tres Esquinas de Boiauassú & TICUNA & Yagua, Cocama \\
\hline RÍO & \multicolumn{3}{|l|}{ ATACUARÍ } \\
\hline 10 & Siete de Agosto & COCAMA & Yagua, Ticuna \\
\hline 11 & San Juan de Atacuari & COCAMA & Yagua, Ticuna \\
\hline RÍO & LORETO YACÚ & & \\
\hline 12 & Santa Clara de Tarapoto & TICUNA & Uitoto \\
\hline 13 & San Francisco & TICUNA & Mestizo \\
\hline 14 & Nuevo Paraíso & TICUNA & Cocama \\
\hline 15 & Santa Teresita & TICUNA & \\
\hline 16 & San José de Villa Andrea & TICUNA & \\
\hline 17 & San Juan de Socó & TICUNA & Cocama, Yagua \\
\hline 18 & Doce de Octubre & COCAMA & Ticuna, Yagua \\
\hline 19 & Santarém & TICUNA & Yagua \\
\hline 20 & San Pedro de Tipisca & TICUNA & Cocama, Yagua \\
\hline 21 & Japón & TICUNA & \\
\hline
\end{tabular}

Fuente: datos recogidos por la autora durante trabajo de campo.

\section{Los asentamientos Ticuna}

Los asentamientos Ticuna localizados hoy en la ribera del río Amazonas colombiano, han vivido un proceso de conformación a lo largo de los últimos 40 años, por lo gen- eral fueron grupos de dos a cinco familias, los que les dieron origen.

Unos de los principales factores que ha condicionado la implantación de caseríos en la ribera del Amazonas ha sido el tipo de paisaje fisiográfico². En función de las

2 Entendido en términos de "unas mismas características mesoclimáticas, morfológicas, de material litológico y de edad dentro de las cuales se espera una homogeneidad pedológica, cobertura vegetal y uso de las tierras. La reunión de paisajes con un mismo origen, se denomina gran paisaje" (Botero, 1997). 
condiciones que ofrece cada uno de ellos a la subsistencia humana, los grupos Ticuna de la ribera han desarrollado sus asentamientos; la llanura de inundación del río Amazonas y algunas de los ríos amazónicos, fueron el hábitat inicial de la mayoría de los grupos que hoy viven en tierras altas. Su presencia en las llamadas tierras de altura, es decir terrazas antiguas y planicies disectadas (o áreas no inundables), es cada vez más frecuente. Véase el mapa No. 3.

El ciclo de inundaciones a que está sometida la zona de várzea y el tipo de vivienda, por los materiales, las técnicas y los espacios mismos que las conforman, no permiten el asentamiento de población numerosa. Los caseríos que existen actualmente en las zonas bajas tienen un crecimiento limitado a pesar de alta productividad que los caracteriza. Estas tierras en las actuales condiciones y con las técnicas que se vienen manejando no permiten pensar en grandes conglomerados de población como los que describieron los cronistas del siglo XVII.

Los caseríos localizados en la llanura de inundación del río Amazonas tienden a desaparecer, en los últimos cinco años, cuatro de estos se han reubicado en otros paisajes fisiográficos (superficies onduladas plio-pleisticénicas y las terrazas antiguas). Sin embargo, en las áreas bajas se siguen desarrollando actividades agrícolas y extractivas.

\subsection{La conformación de un asentamiento de población Ticuna}

El proceso comienza con la construcción de algunas viviendas asociadas a las tierras aptas para el cultivo. Su localización inicial no es definitiva. Presentan diversas formas de distribución espacial, pero siempre en relación directa con el río o caño más cercano, convirtiéndose así, en ejes estructurantes de los asentamientos; la disposición de las viviendas puede ser de forma paralela $o$ perpendicular al río, formando hileras en algunos casos, o dispersa, especialmente aquellos ubicados en áreas de topografía quebrada; en éstos existe un trazado de senderos peatonales orientados hacia el río. Vías de desplazamiento eficaces y fuente de alimento, los ríos, caños y quebradas, es decir el agua, determina los ritmos del tiempo, las actividades económicas, la configuración y simbolización del territorio. Véanse las Tablas No. 4. y No. 5.

Un asentamiento de población Ticuna en la ribera del río Amazonas, está conformado por dos grandes escenarios; son ellos, la cabecera o área urbanizada donde se localizan las viviendas con algunos elementos de infraestructura de servicios públicos y sociales y las zonas de cultivo o chagras, directamente relacionadas con las zonas de pesca, de caza y de recolección. 
En cada uno de estos espacios hay subdivisiones y especialización funcional, que varían dependiendo del paisaje fisiográfico en el que se encuentren. Así en las zonas bajas se ubican cananguchales, áreas de anidación de gaviotas, zona de desove de tortugas charapa (Podocnemis expansa) y taricaya (Podocnemis unifilis), áreas de caza de primates entre otras, mientras que en tierras altas esta oferta disminuye.

En las cabeceras de los asentamientos la disposición espacial de las familias sigue las líneas de la parentela; se identifica cierta jerarquía espacial dentro de los mismos, con la presencia de un centro sobre el cual giran y se desenvuelven las principales actividades de la comunidad; estos son la escuela, el hogar infantil, el puesto de salud, el templo y los escenarios deportivos.
La presencia de la cancha de fútbol y/o canchas múltiples reviste importancia significativa en cada asentamiento, existe en todos ellos y es un elemento organizador del espacio urbano, pues junto a estas también se ubican viviendas.

Rodeando los caseríos se encuentra el área de cultivo o zona de chagras, donde se desarrolla la llamada agricultura migratoria. Cada chagra constituye una unidad de producción familiar donde se da una clara división del trabajo por género. La producción se desarrolla mediante un proceso de zocola, tumba, picada y descomposición o quema de coberturas vegetales naturales y seminaturales, conformando espacios que no superan en promedio las 2 hectáreas (Acosta, 1999). 
Tabla No. 4

Formas de implantación de los caseríos Ticuna en la ribera del Amazonas colombiano

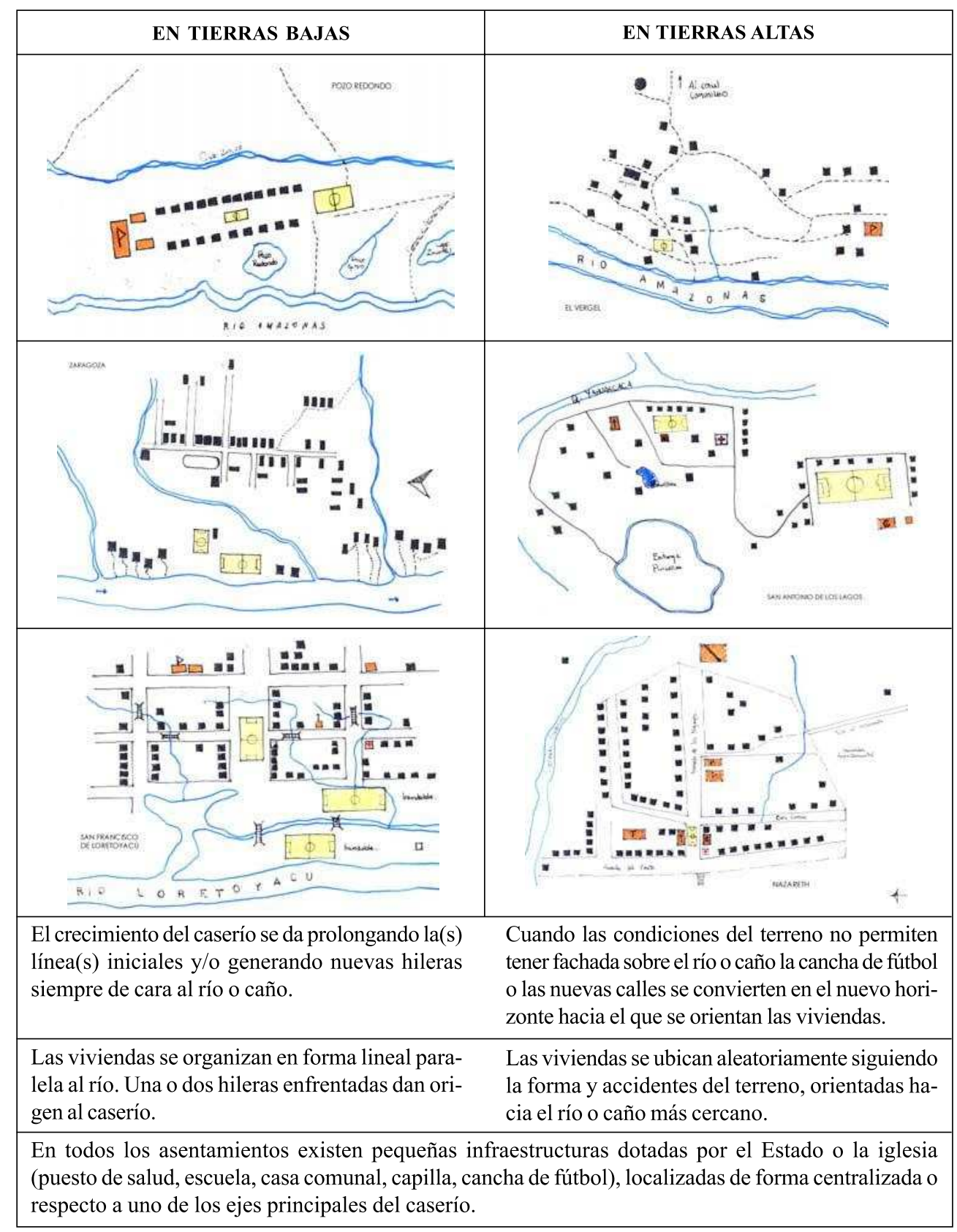

Fuente: la autora.

I 4 Elizabeth Riaño Umbarila 
Tabla No. 5.

Esquemas de las cabeceras de los asentamientos de la ribera del Amazonas y la forma como se van estructurando tejidos urbanos, a medida que crece el grupo

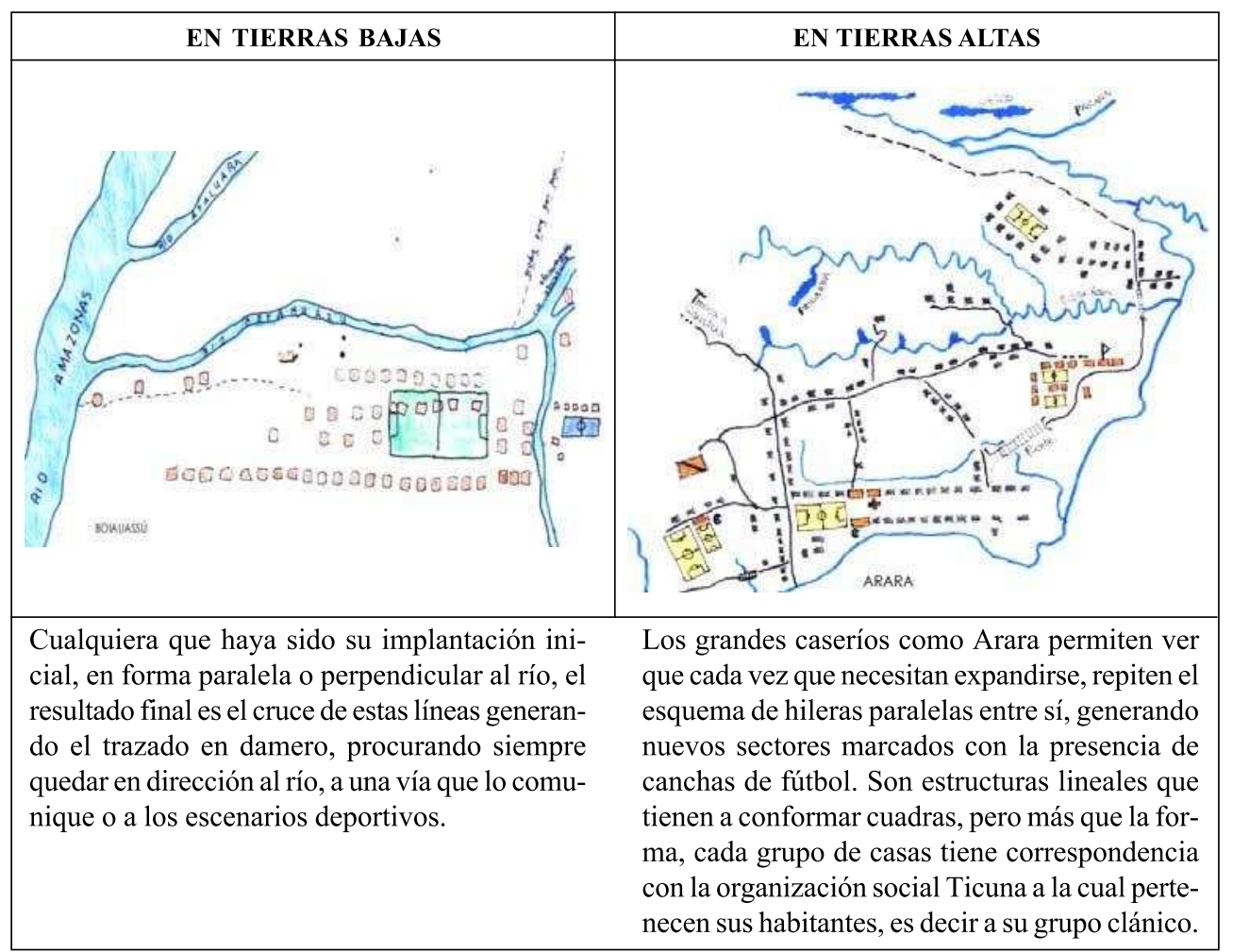

Fuente: la autora.

\subsubsection{La cabecera del asentamiento}

La cabecera de los asentamientos de la ribera está constituida por las viviendas, las obras de infraestructura de servicios públicos, las pequeñas infraestructuras de servicios sociales provistas por el Estado y los escenarios deportivos.

\subsubsection{La vivienda actual en área rural, casa monofamiliar}

Durante el siglo XX la casa de los Ticuna ha sufrido un acelerado proceso de transformación. Hacia los años treinta aún habitaban en malocas, pero para los Ticuna de hoy, en su memoria sólo queda como idea de "casa antigua" aquella unidad monofamiliar construida en caraná (Mauritia caraná), piso en pona (Paxiuba) levantada del terreno, a la cual se accedía por un tronco horadado a manera de escalera, a un único espacio. La construían muy alta a fin de protegerse de las "fieras" según el relato de los abuelos. 
Aquellas viviendas albergaban esencialmente a una familia nuclear (padres e hijos), eventualmente a algunos familiares o a una nueva familia (hijo o hija recién casados) quienes aún no habían construido su casa. Véase la figura No. 1.

Para la gente Ticuna de hoy, la casa tradicional dejó de ser la maloca, pues no se identifican con ella, probablemente porque para ellos es signo de atraso; ven a sus "paisanos" del río Cotuhé como "incivilizados", como "inferiores", como "gente que vive en maloca", mientras que los de la ribera del Amazonas aspiran a vivir y están configurando áreas urbanizadas.

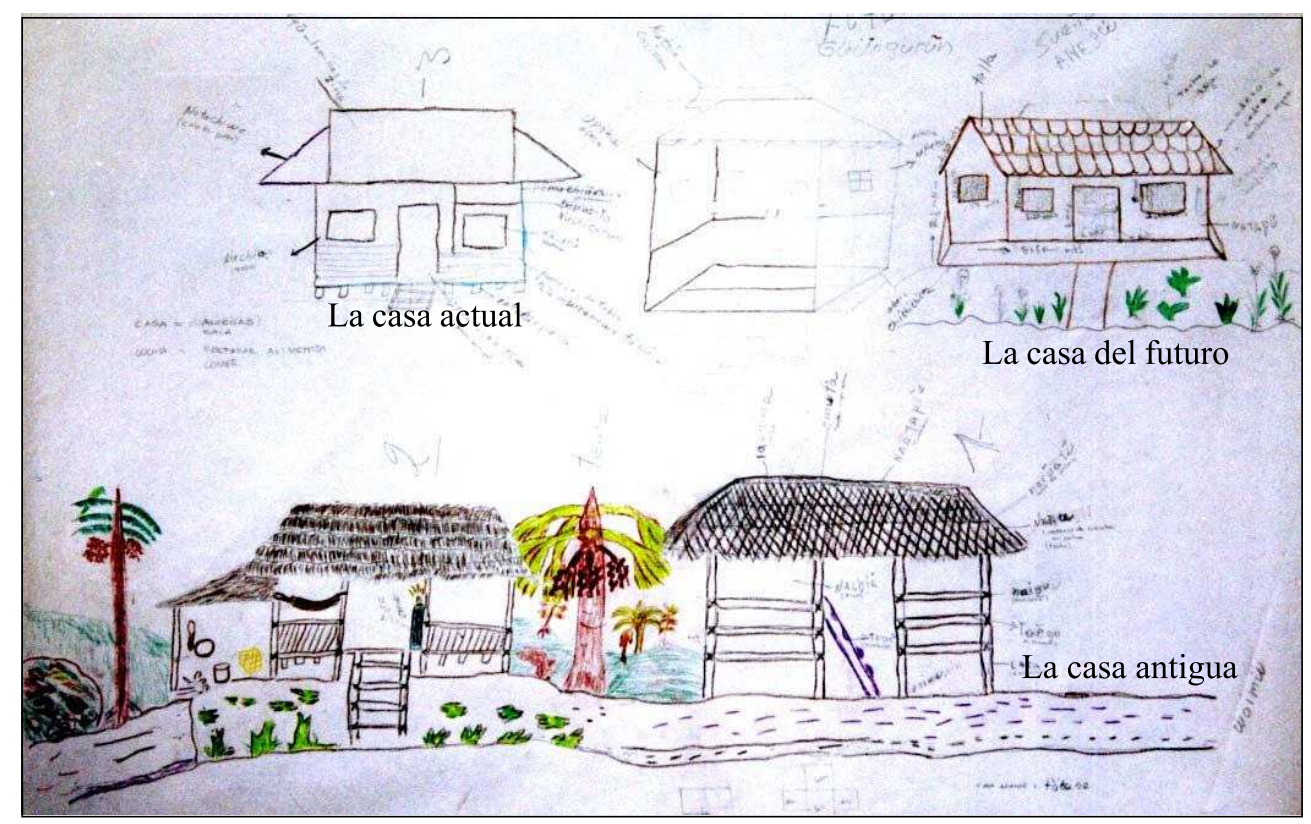

Figura No. 1. La casa antigua, la casa actual y la casa del futuro.

Fuente: dibujo elaborado por los adultos de la comunidad de Nazareth, junio de 2000.

Por ello cualquier intento por "recuperar" la maloca como casa tradicional no pasa de ser un esfuerzo por recrear la imaginación de turistas, pues carece de la cosmovisión que la maloca poseyó, que la gente que las construía le incorporaba.

Con la progresiva ubicación de los Ticuna en las márgenes e islas del Amazonas, se introdujeron las plataformas con pilotes para evitar las inundaciones debidas a la creciente del río. Las actuales viviendas de los Ticuna en la ribera del Amazonas, son casas construidas sobre una plataforma que a su vez se levanta sobre pilotes (estructura elevada del suelo). Véase la foto No. 1. 
A través de la lectura del espacio de la casa, se evidencian los cambios que paulatinamente se han incorporado a partir de la influencia de la otra cultura. La casa de los Ticuna se ha hecho más compleja. Una plataforma cubierta constituyó durante varias décadas la vivienda de los Ticuna. Un espacio así los defendía de la lluvia y el sol y les servía como refugio. Sólo existían pequeños muros a modo de paravientos. En esta unidad mínima de vivienda para una familia, el fogón se ubicaba en el suelo. Actualmente esta es la primera fase de las viviendas de hogares jóvenes. Véase la Figura No. 2.

En la siguiente fase de desarrollo, el fogón se instala sobre la misma plataforma en uno de sus extremos y los cerramientos

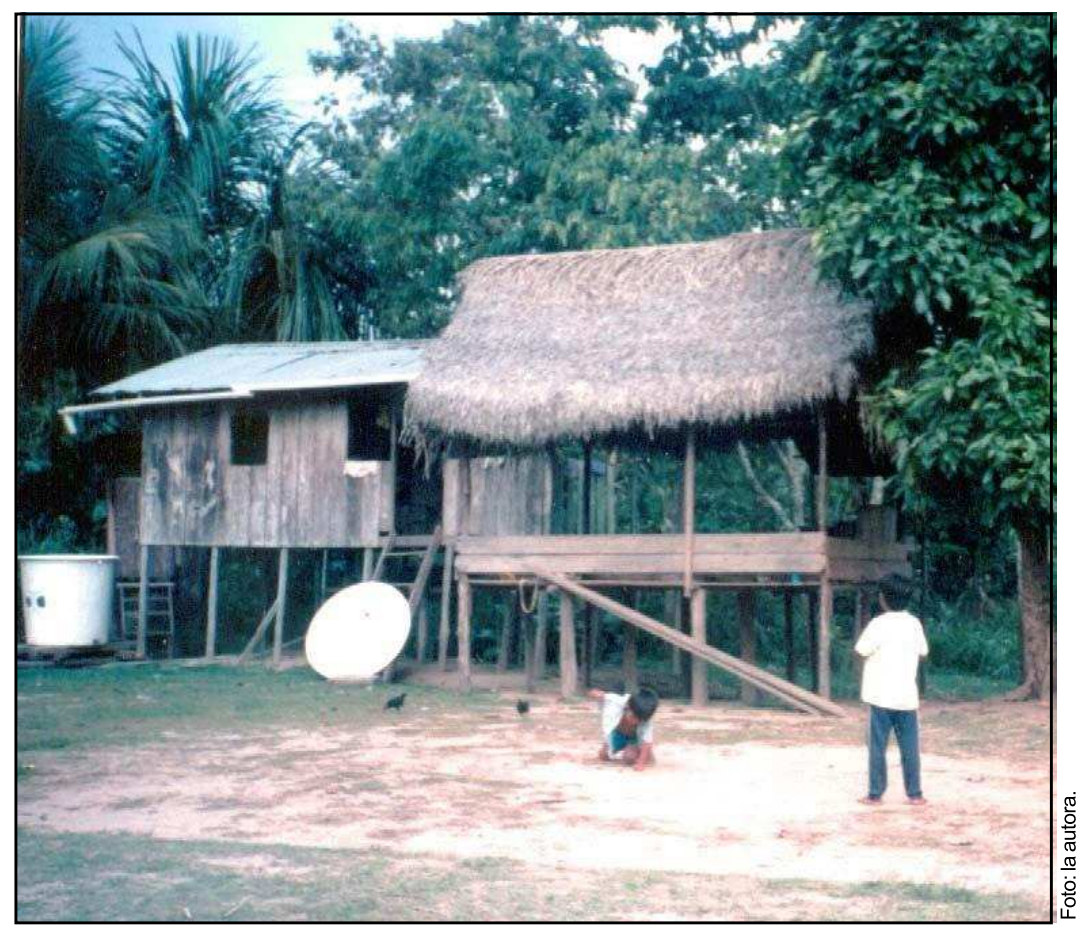

Foto No. 1. Casa de una familia Ticuna en la comunidad de Pozo Redondo, 1995.

aparecen en mayor longitud y altura, hasta conformar dos espacios bien diferenciados, uno de dormir y otro de estar donde se encuentra el fogón. Véanse las Figura No. 3. y No. 4.
A esta unidad básica se le pueden ir adosando nuevos espacios, situación vinculada al aumento de los miembros del grupo familiar. Cada vez es más notoria la diferenciación funcional de cada uno de estos espacios y se introduce un nuevo 


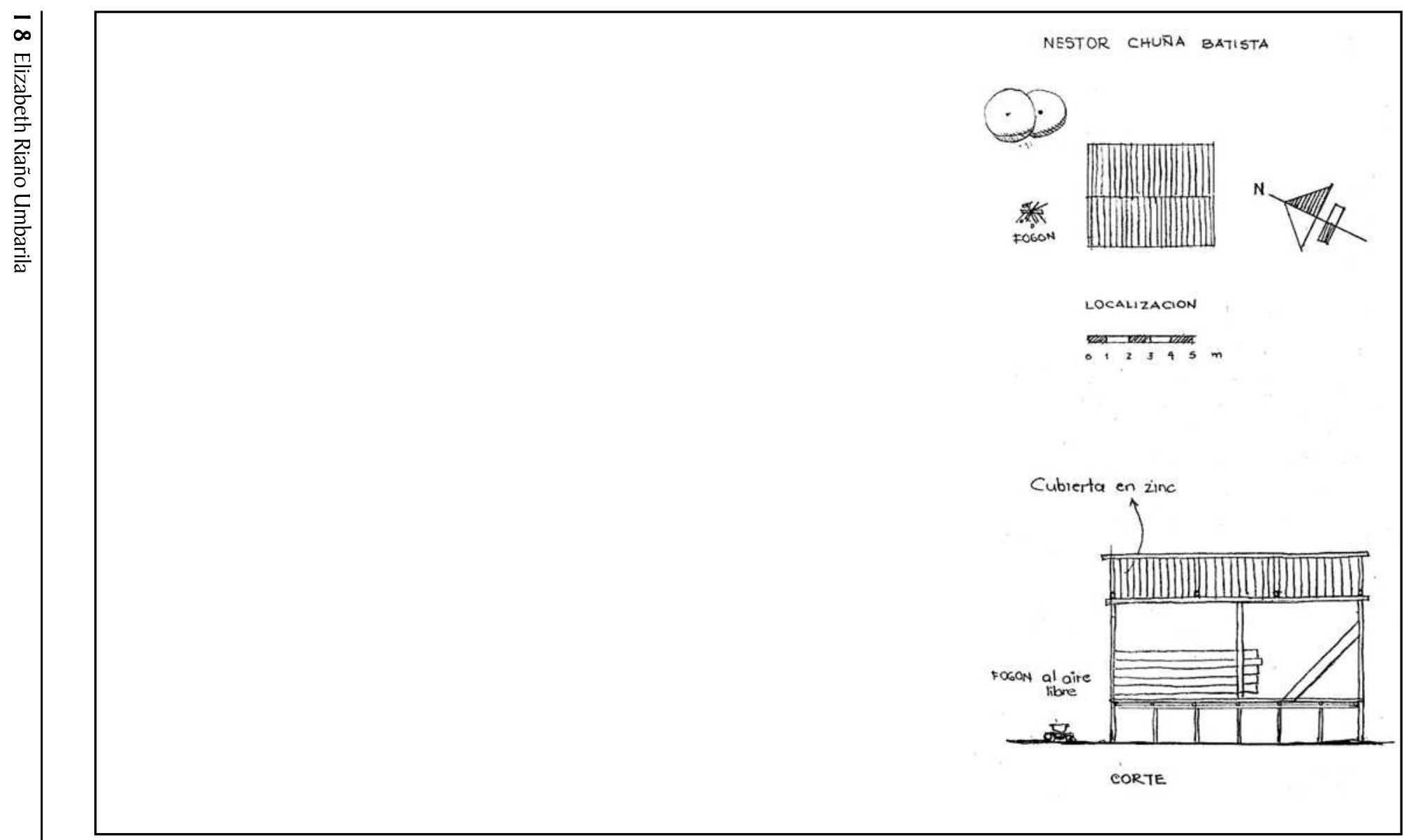

Figura No. 2. Casa 1, espacio único con fogón en el piso, cerramientos a modo de paravientos. Fuente: dibujo elaborado por los adultos de la comunidad de Nazareth, junio de 2000.
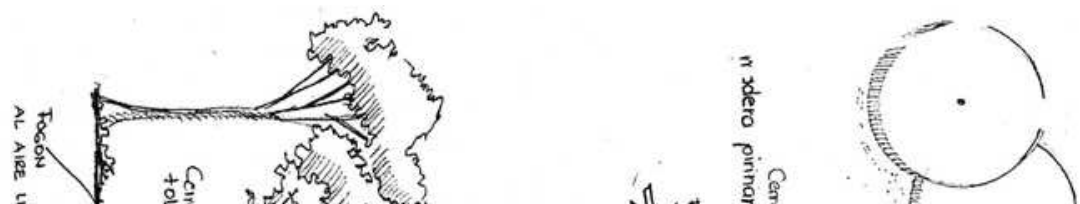


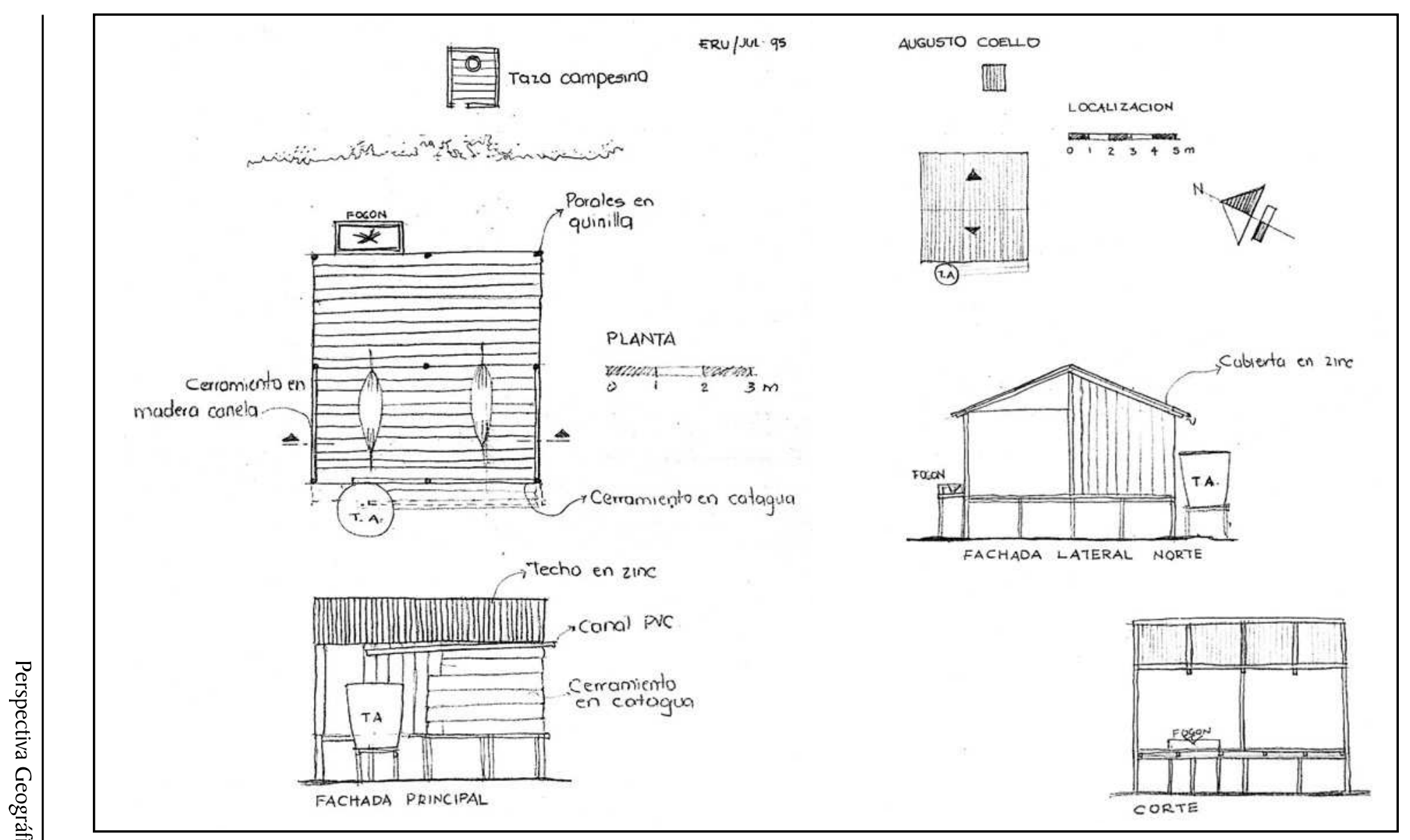

Figura No. 3. Casa 2, espacio único con fogón sobre la plataforma. Fuente: la autora. 


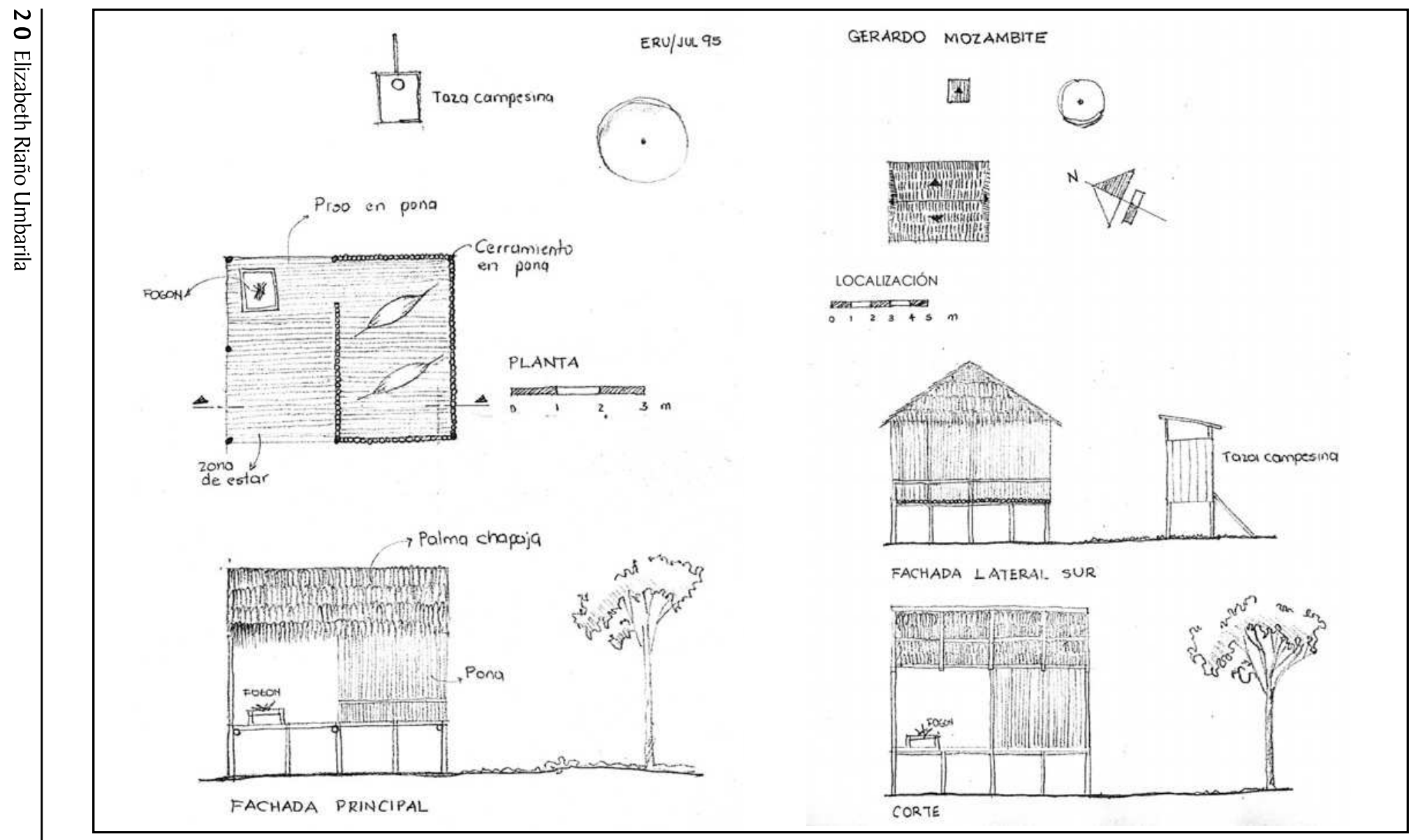

Figura No. 4. Casa 3, diferenciación espacial zona de dormir con cerramientos, zona de estar abierta y con fogón. Fuente: la autora. 


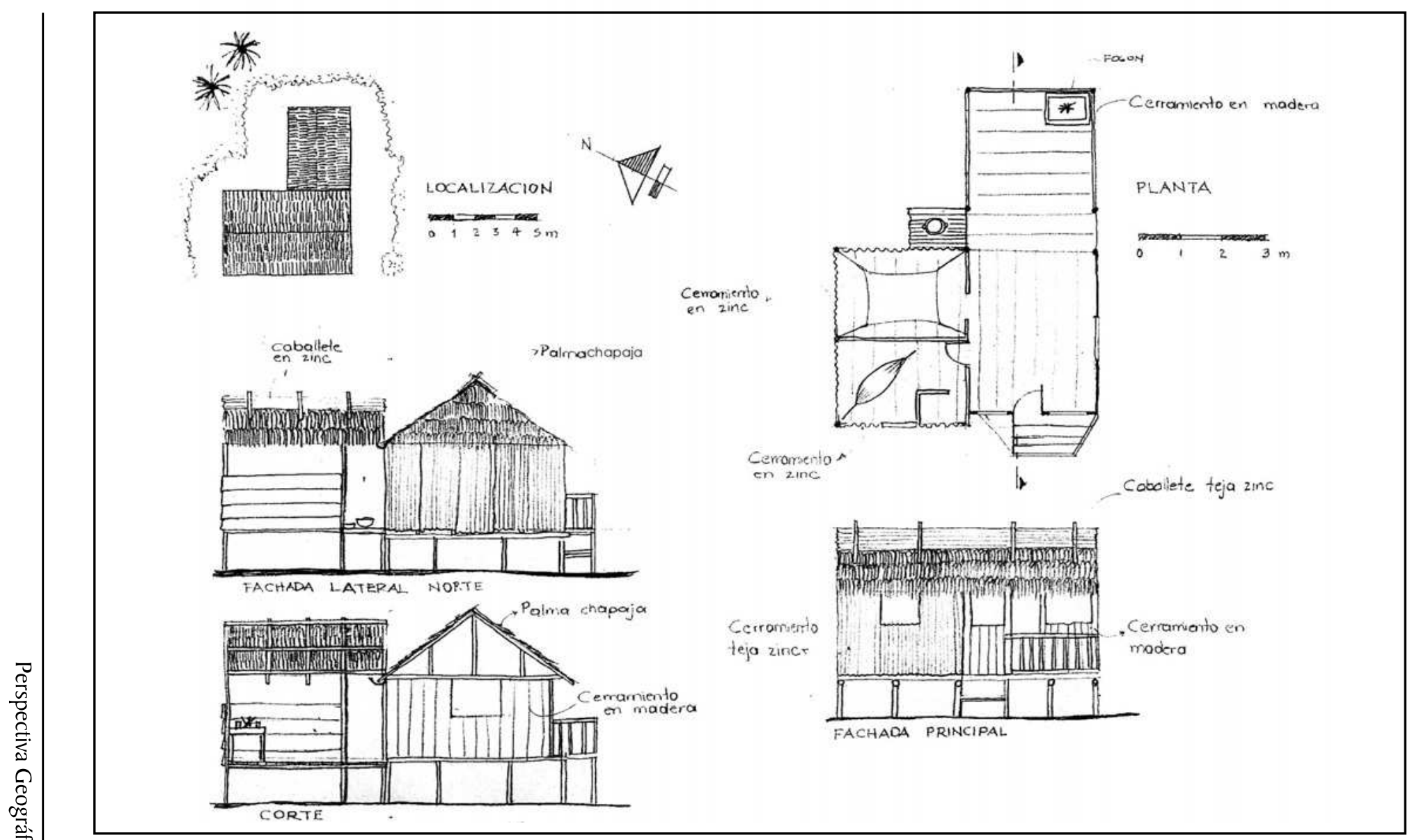

Figura No. 5. Casa 4, aumenta el número de espacios y las divisiones cumplen funciones específicas (dormitorio, zona de estar, cocina). Fuente: la autora. 


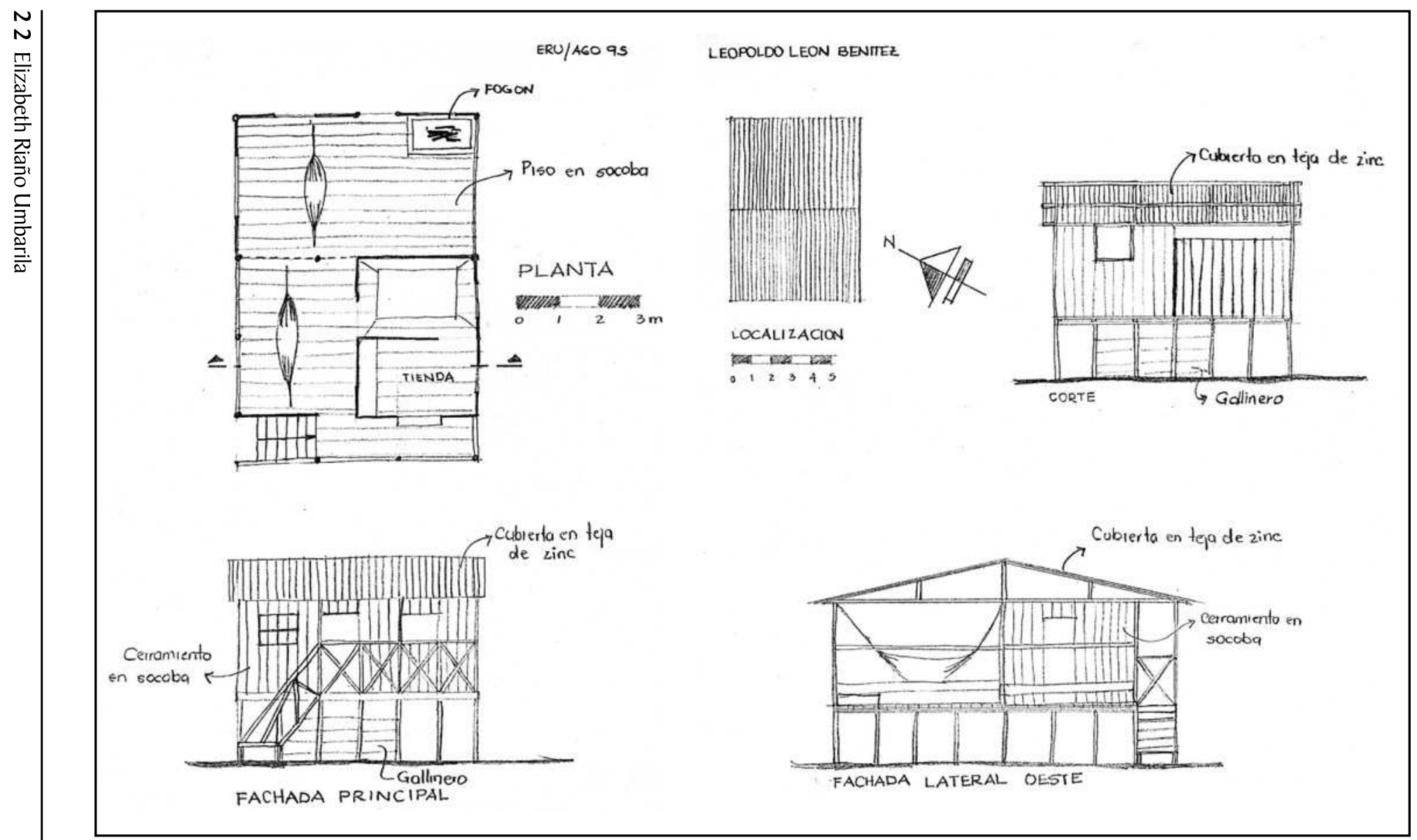

Figura No. 6. Casa 5, se mantienen las divisiones y la especialización de funciones en cada uno, aparece un nuevo elemento: la tienda. Fuente: la autora. 
elemento, la tienda. Véanse las Figuras No. 5. y No. 6.

Este espacio habitacional consta de tres estratos en sentido vertical así:

a. Las viviendas de esta zona están construidas sobre pilotes o estantillos de madera (quinilla) cuya longitud promedio oscila entre 0.50 y $2.00 \mathrm{~m}$. Los estantillos soportan la estructura de una plataforma que constituye el piso de la casa. El espacio formado entre el terreno y la plataforma permite la circulación del aire, protege de la entrada de animales y aísla de la humedad, favoreciendo la conservación de la madera con la cual se construye la plataforma. Este espacio es frecuentemente utilizado como refugio para gallinas, cerdos, patos o perros, y sirve también para guardar madera y algunas herramientas del trabajo.

b. El segundo estrato lo conforman el piso de la casa o plataforma y los travesaños del techo, es un espacio intermedio donde se desarrollan las actividades cotidianas. Los materiales de pisos y cerramientos (muros) son tablas de madera o pona (yaripa). En éstos últimos se usa ocasionalmente zinc, cartón o plásticos.

c. El tercer estrato está delimitado por el techo y los travesaños que lo sostienen conformando el volumen de cubierta. A veces se colocan sobre los travesaños tablas a manera de zarzo que sirven para guardar objetos o para dormir cuando no hay suficiente espacio. La estructura de madera a manera de cieloraso con la que se construye permite reducir la concentración de calor que acumula y transmite la teja de zinc.

Con el tiempo se ha generalizado el techo de lámina de zinc aunque en varias viviendas se mantiene el techo en hoja de palma (caraná, yarina o chapaja), particularmente en las cocinas. Sin embargo, aunque la hoja da frescura a la construcción, se deteriora rápidamente y es necesario cambiarla cada cierto tiempo.

De acuerdo con el tipo de hoja y el sistema de trenzado, el tiempo de duración de un techo oscila entre año y medio y tres años. La mayor desventaja de este material es que favorece la presencia de roedores, insectos y murciélagos generando problemas sanitarios; de otro lado, cada vez es más limitada la obtención del recurso, la deforestación de las palmas se ha intensificado y es difícil conseguir las hojas. Hoy tener casa con teja de zinc, tiene una connotación de avance y progreso, aunque es inferior en términos de confort.

En sentido horizontal (planta) en la casa de hoy se identifican varias zonas cuya función puede cambiar a lo largo del día:

a. Zona de estar, es un espacio multifuncional, allí se reciben visitas, se reúnen las familias, los niños juegan y realizan labores escolares y los adultos realizan objetos artesanales. En este espacio también se guindan hamacas durante el día. El mobiliario lo constituyen mesas y butacos, es el sitio donde se ubican algunos radios, grabadoras e implementos de trabajo. 
Algunas viviendas tienen un pequeño espacio destinado para tienda donde se venden diferentes artículos cumpliendo funciones comerciales. Son frecuentes las divisiones en la zona de estar, utilizadas como espacios para dormir. Aunque no son amplios, durante las noches toda la familia se acomoda allí. Cuando hay chinchorros generalmente se utilizan para descansar durante el día.

b. Zona de dormir, constituida por espacios más cerrados con esta función única. El uso de las divisiones entre dormitorios es cada vez más frecuente. Esta situación tiene una fuerte influencia religiosa, pues en algunas comunidades se reitera la necesidad de separar la habitación de los padres de las de sus hijos. Hoy se duerme casi siempre en el piso de tabla o de pona, sobre una sábana o cobija acompañada de un toldillo, salvo algunas personas que lo hacen en camas cuyo uso viene en aumento. El toldillo es imprescindible para poder dormir ya que en la noche proliferan los zancudos.

c. Zona de cocina, este concepto es diferente al de la población no indígena, pues en algunos casos pueden referirse al fogón, componente mínimo. Este puede estar ubicado dentro de la casa como una prolongación de esta o de manera independiente comunicada por un puente. Alrededor del fogón se articulan el espacio para comer, mesas, repisas para platos, ollas y elementos para la preparación y consumo de alimentos. En la mayoría de los casos la zona de cocina es un espacio separado de la zona de estar y se convierte en una de las zonas privadas de la vivienda. Por lo general está ubicada en la parte trasera de la vivienda, aunque es el lugar más deteriorado, normalmente la familia se reúne allí o cerca al fuego a la hora de las comidas.

d. El fogón es una caja rectangular de unos $30 \mathrm{~cm}$ de altura, que contiene tierra apisonada; cuando no existe un área destinada como cocina el fogón se ubica en un extremo de la plataforma, en el exterior de la casa o el algunos casos bajo la plataforma, cuando su altura lo permite. Cerca del fogón se ubica una estructura que sirve de apoyo para el lavado de los platos ("pasera"), generalmente a su lado esta el tanque de agua, cuando lo poseen. Colgados de las vigas del techo o de las paredes hay canastos fabricados por ellos mismos donde se guardan plátanos, yuca $\mathrm{u}$ otros alimentos. En algunos casos, también hay una especie de zarzo donde se colocan productos que traen de la chagra u otro tipo de objetos.

El fogón familiar, invariablemente lleva una rejilla portátil, es el moqueadero o ahumadero para secar carne, hecho de tres varas atadas juntas en el extremo superior en forma de trípode, entre las patas se ata la rejilla. Algunas comunidades disponen de un fogón comunal para tostar la fariña y es un sitio de reunión importante para las mujeres y sus niños. Los procesos de preparación de alimentos como el casabe, la fariña, el masato y las carnes ahumadas, requieren no sólo hornos o fogones y calores diferentes (maderas de combustión lenta ó rápida, maderas que produzcan mucho 


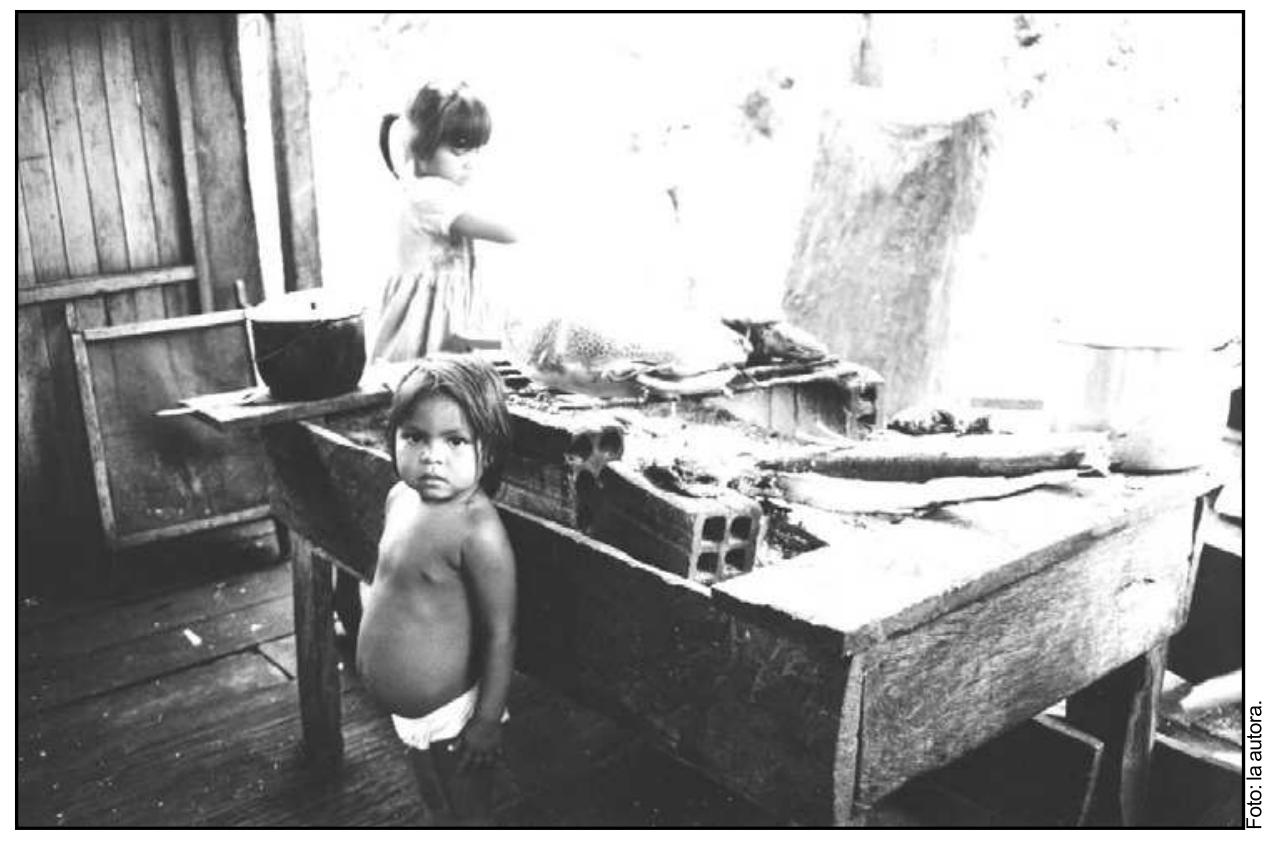

Foto No. 2. Fogón de leña.

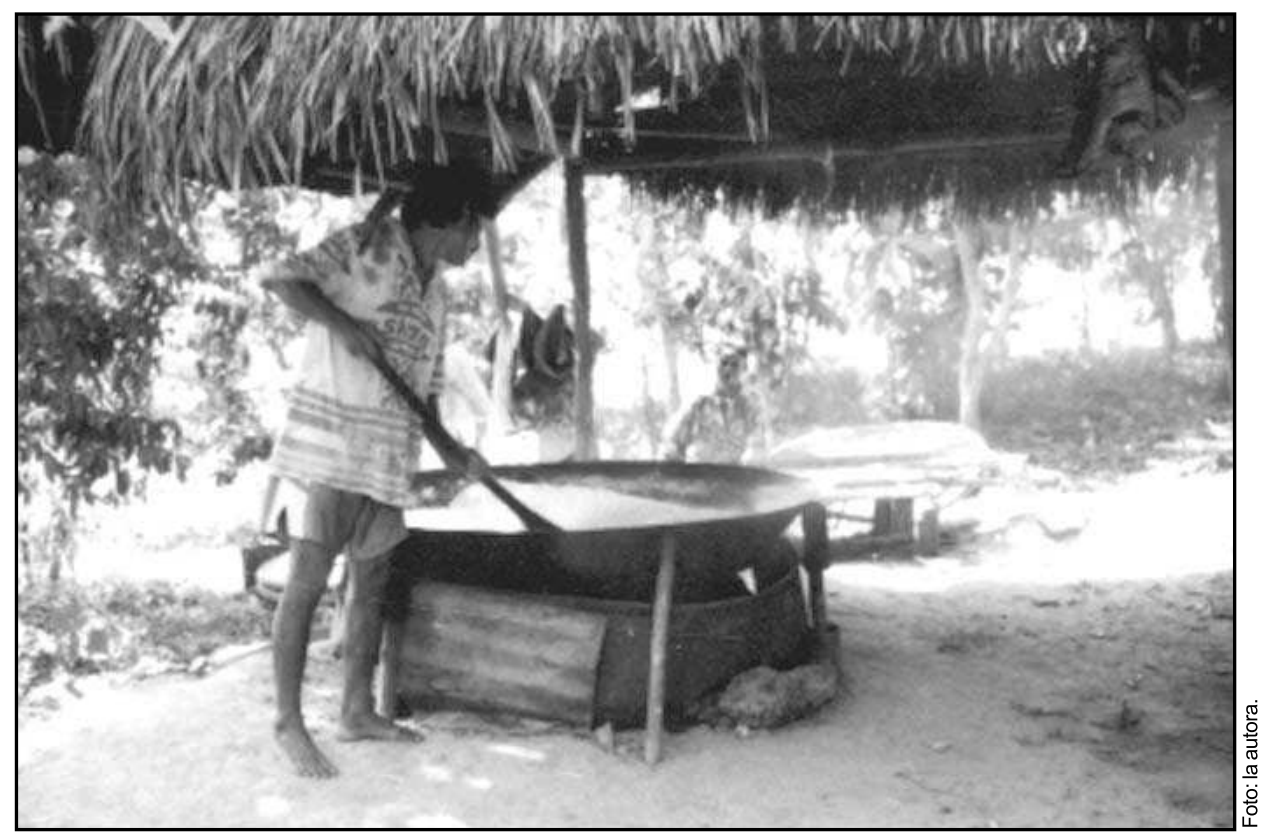

Foto No.3. Horno para tostar fariña 
humo), sino un espacio amplio y disponible durante varias horas.

El uso del fuego es uno de los elementos que ha debido acomodarse a las nuevas condiciones de habitación y se considera que sigue en proceso de cambio.

El fogón constituye un buen indicador de la transformación habitacional. Siempre están pensando donde puede funcionar mejor y por el uso de materiales perecederos en la construcción de ese espacio, siempre tiene opción de transformación, es el espacio de la vivienda que sufre mayores cambios a lo largo de la vida de una familia contemporánea.

Podría decirse que el lugar del fuego en la casa de los Ticuna ha permanecido en constante movimiento y la tendencia de hoy es a estabilizarse. Se observa también, un mayor grado de especialización de la zona de cocina y una clara definición del lugar de los elementos agua y fuego. El fuego producido por la combustión de la madera empieza a remplazarse lentamente por el gas, la energía eléctrica $\mathrm{y}$ en algunos casos por la gasolina o el petróleo. Sin embargo, el alto costo de los combustibles hace que predomine el uso del fogón de leña, sólo las pocas familias que reciben ingresos o tienen un salario pueden comprarlos.

Desde la cocina la mujer controla visualmente todo el espacio y los movimientos de los niños. Este universo cotidiano es «abierto» y permite una comunicación fácil con las demás cocinas. Alrededor de las viviendas se pueden encontrar jardines con plantas ornamentales, medicinales o aromáticas y frutales como zapote, bacaba, coco, guamas, uva caimarona, caimo, copoazú, etc. Algunas veces árboles frutales y jardines son cercados con botellas colocadas en forma invertida una al lado de otra. Son frecuentes los semilleros en platones, restos de canoas e incluso en estructuras elevadas de forma cuadrada, rellenas de tierra. El panorama se completa con los corrales para gallinas o patos y eventualmente para cerdos. Cuando hay taza sanitaria, está ubicada en la parte trasera o lateral de la vivienda, a unos cuantos metros.

\subsubsection{Espacio central del caserío con presencia de pequeñas infraestructuras estatales}

Las principales infraestructuras que generalmente se concentran en un sector del caserío corresponden al puesto de salud, a la sede comunal, a la capilla o templo (católico o evangélico), la escuela y el jardín comunitario.

En los asentamientos donde hay un puesto de salud trabaja un promotor, quien hace parte de la comunidad y ha sido capacitado por la Secretaría de Salud Departamental; él se encarga de mantener actualizada la información referente a los datos de la población, las viviendas y el saneamiento básico; presta también atención a casos sencillos de curación y prevención; para esta tarea disponían de algunos materiales necesarios en el cuidado de este tipo de 
casos, hasta que se promulgó la Ley 100 de Seguridad Social, hoy solo cumplen el papel de remitentes de pacientes. Los puestos de salud no pueden funcionar por falta de medicamentos, por deterioro de las instalaciones o por carecer de equipos de comunicación, radio, bote y/o motor.

Respecto al servicio educativo ${ }^{3}$, este se presta a través de tres instancias: el Fondo Educativo Regional, que administra los recursos del situado fiscal; la Coordinación en Educación, institución dirigida por la Prefectura Apostólica de Leticia, administra la educación en algunas escuelas rurales del departamento, básicamente los internados indígenas y los municipios de Leticia y Puerto Nariño que aportan con recursos propios.

No obstante, la planta de maestros de las escuelas casi nunca esta completa y de otro lado, el perfil de los educadores es muy bajo, la mayoría son bachilleres normalistas, sólo se contaron 7 licenciados en toda la ribera del Amazonas.

En algunos resguardos, con los dineros de transferencia se compran los uniformes de los muchachos que estudian bachillerato.
La educación para los Ticuna constituye el único medio que les permitirá acceder al mercado laboral compitiendo con los blancos, pero existen grandes dificultades pues, si quieren cursar el bachillerato deben salir a internados fuera de su grupo social con lo que se van alejando de su comunidad llegando a romper vínculos. Ya no se sienten identificados con su territorio y los ancianos los miran con cierto recelo, estos jóvenes se encuentran ante la ambigüedad de no sentirse identificados con una situación u otra.

Durante la etapa de educación básica primaria y por efecto de la Ley de Etnoeducación, los niños reciben clases en Ticuna y en español, pero en quinto de primaria todo el programa es dictado en español. Cuando no hay preescolar en la comunidad los niños tienen problemas para desplazarse hasta aquellas donde lo dictan.

La presencia de las escuelas en los caseríos de la ribera aceleró el proceso de sedentarización de la población y el crecimiento de la misma, pues un determinante en la elección del lugar donde una familia va a vivir, es que aquel le ofrezca educación a sus hijos.

Las escuelas funcionan en condiciones precarias, la planta física ofrece apenas

\footnotetext{
3 Antero León Macedo, profesor Ticuna de la comunidad de Macedonia relata algunos aspectos acerca del tema: "Hacia 1940 existió en Puerto Nariño un orfanato, ese fue el primer internado. Del orfanato los niños huían, pero poco a poco se fueron acomodando. Los que salían del internado eran los que no querían volver a hablar el idioma. Cuando yo era niño en Puerto Nariño todos hablaban Ticuna. No sabían mucho español, con la aparición de la escuela y el internado los que salían de allí se avergonzaban de su lengua". Gerardo Ahué, hombre Ticuna de 54 años habitante de Puerto Esperanza, recuerda que fue al internado de Puerto Nariño hacia 1954, "había más educación en ese tiempo porque aprendimos a la fuerza. Nos exigían mucho. Las clases eran en español. No enseñaban Ticuna".
} 
las mínimas condiciones de confort a alumnos y maestros, la mayoría se encuentra deteriorada y las baterías sanitarias no funcionan; el material didáctico es insuficiente y desactualizado, pero principalmente es descontextualizado. La accesibilidad a las escuelas es deficiente pues muchos niños deben caminar largas distancias o hacer recorridos en canoa.

El Instituto Colombiano de Bienestar Familiar, desarrolla los siguientes programas en el área: Hogares Comunitarios, respecto a lo que se comenta, "ahora hay quien cuida los hijos y las madres pueden ir a las chagras, ya no se preocupan por el almuerzo porque allí se los dan y ellas pueden hacer sus labores". Este es un programa con vocación urbana funcionando en área rural e indígena. También funcionan los Jardines Comunitarios, que cuentan con "dinamizadores" hablantes de las dos lenguas, español y Ticuna, con la intención de que los pequeños aprendan ambas.

Siguiendo con las intervenciones desde el Estado, tenemos el Programa de Saneamiento Básico y Mejoramiento de Vivienda, el cual constituye uno de los factores de transformación más fuerte y reciente que han experimentado los asentamientos. Con recursos del Plan Nacional de Rehabilitación (PNR) en 1993 y posteriormente en 1995 con la Red de Solidaridad Social, se construyeron módulos de vivienda que permitieron la ampliación de las casas existentes o la generación de gérmenes de vivienda. Estos proyectos cambiaron el aspecto de todos los asentamientos de tal manera que la imagen urbana apenas delineada se definió claramente.

El proyecto fue bien recibido en la medida que todo lo que llegue a estos caseríos para ellos significa ganancia, sin embargo, hay insatisfacción porque las expectativas generadas las interpretaron como el acceder a una vivienda nueva y no al mejoramiento de una parte de esta, como lo planteaba el programa. No obstante, para muchos si tuvo este significado, tanto que algunos se han despreocupado por optimizar el lugar donde viven en espera de un nuevo proyecto financiado por el Estado. A pesar de lo anterior es necesario destacar tanto la versatilidad del módulo propuesto como la creatividad de los Ticuna, pues lo han adaptado a sus necesidades en función de su organización familiar y social.

\subsubsection{Infraestructura de servicios públicos}

La concentración y aumento de población en los caseríos, crea nuevas condiciones de permanencia a largo plazo, los cambios ambientales y técnico económicos tales como la sobreexplotación de la periferia cultivable, la deforestación y erosión, cambios en las actividades productivas $y$ nuevos hábitos alimenticios $\mathrm{y}$ habitacionales, derivan en problemas sanitarios. La disposición de excretas y basuras es deficiente y aunque en un alto porcentaje cuentan con la taza sanitaria (inodoro en porcelana conectado a un tubo PVC que desagua en un pozo séptico), las fallas de instalación y manejo reducen

28 Elizabeth Riaño Umbarila 
su eficiencia y beneficio. A esto se suma la irregularidad en la disposición de agua necesaria para su adecuado manejo y control sanitario. Muchos dejan expuestas las excretas al aire libre. Las basuras también son expuestas al aire presentándose alta concentración de basura en ciertos lugares lo cual genera graves problemas de contaminación.

\section{a. Agua potable}

El suministro de agua potable, proviene de aguas lluvias recolectadas a través de tanques de 500 litros, generalmente con muy baja cobertura. En época de verano tienen problemas por escasez del líquido y la gente lo suple transportándolo desde el río. Es una tarea dispendiosa, además de la baja calidad que presenta ya que puede generar enfermedades de tipo gastrointestinal y epidérmico. En algunos asentamientos existen acueductos locales que funcionan irregularmente (falta el suministro de energía, daño de las motobombas, falta de combustible) se alejan de la eficiencia mínima, pues no brindan la calidad, cantidad, regularidad y cobertura necesarias.

\section{b. Alcantarillado y evacuación de excretas}

El servicio de alcantarillado no existe en la zona rural. El manejo de aguas negras se hace por medio de pozos sépticos y tazas sanitarias que se ubican en pequeñas casetas de madera; reiteradamente la Secretaria de Salud Departamental promueve el mantenimiento y construcción de las mismas, pero su funcionamiento no es permanente. En las zonas inundables se presentan problemas de revertimiento de su contenido, ocasionando un problema sanitario mayor $y$ en las tierras altas la dificultad consiste en obtener el agua que permita mantenerlas limpias, generando el abandono de éstas.

El uso de la letrina más que una alternativa se convierte en un foco séptico por el mal mantenimiento. Las tazas sanitarias en muchas ocasiones no son utilizadas o no son instaladas. Si se tiene en cuenta que la mayoría de los habitantes se encuentran concentrados en poblados, los problemas de salud se vuelven agudos ya que los niños y animales deambulan por el mismo lugar donde hay deposiciones y basuras.

\section{c. Basuras}

El manejo que se da a las basuras, difiere en una y otra comunidad siendo lo más usual enterrarlas, quemarlas o arrojarlas al río. La presencia de elementos como plásticos, latas y vidrios es cada día mayor $\mathrm{y}$ algunas veces los utilizan para otras funciones, por ejemplo, entierran las botellas a crear cercados que sirven como materas.

\section{d. Los escenarios del deporte}

En todas las comunidades indígenas de la ribera del Amazonas y las del sector de la carretera, la cancha de fútbol desempeña un papel fundamental en la vida cotidiana. Es uno de los lugares donde se encuentran, comparten, se 
divierten y practican deporte. Allí se acude con alegría y entusiasmo, mientras que al lugar de reuniones comunitarias se acude por curiosidad o por responsabilidad. La cancha juega un papel preponderante en la estructura de la distribución espacial del asentamiento pues se prefiere tener la casa muy cerca de esta. Desde Leticia hasta Atacuari y Tipisca, existen en total de 27 canchas de fútbol, 24 canchas de micro fútbol en tierra y 3 en concreto, 2 canchas de minifútbol, 19 canchas múltiples y 3 parques, aquí se excluyen los escenarios del casco urbano de Leticia y Puerto Nariño. La actividad futbolística es intensa, se organizan campeonatos intercomunidades a lo largo del año y la participación femenina es constante $\mathrm{y}$ creciente.

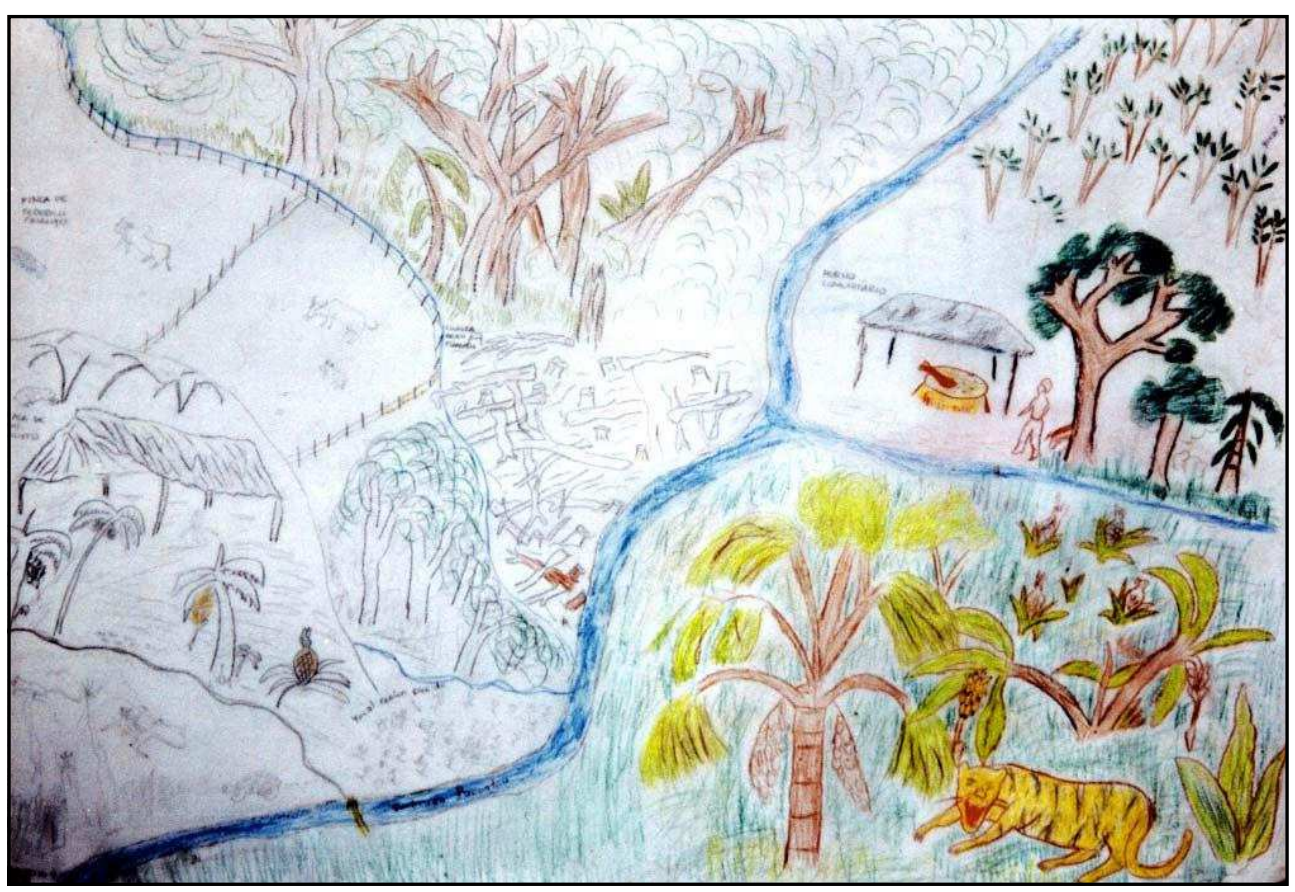

Figura No. 7. La Chagra.

Fuente: dibujo de los jóvenes Ticuna de la comunidad de Nazareth, junio de 2000.

\subsubsection{El entorno de la cabecera}

Las zonas de cultivos o chagras, y las zonas de caza, pesca, recolección y extracción de productos el bosque, cercanos a los caseríos (en distancias que no superiores a una hora, caminando o remando), constituyen el centro de las 
actividades económicas de los Ticuna, lo cual les permite garantizar su subsistencia.

Veamos a continuación las algunas características de las estructuras económica, social y político-administrativa de los Ticuna.

\section{Estructura Económica}

Las actividades productivas desarrolladas por los miembros de las comunidades se destinan al autoconsumo. La agricultura, la pesca, la caza y la recolección son las principales. Cada familia tiene un área de cultivo o chagra donde siembra yuca, maíz, plátano, mediante el sistema de tumba, roza y quema. Cuando producen algún tipo de excedente proveniente de la pesca o la agricultura lo comercializan en Leticia o Puerto Nariño, obteniendo pequeñas sumas de dinero con las cuales adquieren los productos complementarios de su dieta alimenticia, como azúcar, arroz, aceite, etc. De acuerdo con Acosta (1999), en las chagras se identifican diferentes fases de producción teniendo en los primeros estratos especies de pan coger y árboles frutales y en los últimos maderables y palmas de tardío rendimiento.

Acosta (1999), citando a Hammond, Dolman y Watkinson (1995), quienes realizaron estudios en la comunidad de Palmeras, afirma que "la práctica agrícola esta siendo modificada por las fuerzas del mercado y se encuentra en estado de transición. Lo cual se constata por la existencia de especies cultivadas de las cuales un $23 \%$, corrientemente se destina para la producción de algún excedente posible de ser comercializado; un $20 \%$ del área adecuada y destinada para los espacios cultivados se reserva para la siembra de especies cuya producción se espera comercializar en el mercado. Esto ha llevado a la especialización del sistema de siembra en monoculturas de yuca y/o plátano en pocas chagras. Lo anterior muestra una transición hacia una práctica agrícola corriente del sistema de producción no indígena". Los mismos autores afirman que la integración de la producción orientada hacia el mercado puede producir tanto beneficios potenciales como consecuencias a la comunidad, al modificar el tradicional sistema agrícola.

La pesca, es una actividad que realizan en relación dependiente de un patrón bajo una relación salarial y de endeude, otros combinan esta actividad con la agricultura de subsistencia.

Conservan prácticas artesanales en cestería, cerámica y tejidos de cortezas decoradas, que les son útiles para el comercio con colonos y turistas. Estos grupos indígenas, presentan diferentes grados de articulación con la economía de mercado y sus territorios están siendo sometidos a procesos de colonización y desarrollo de economías extractivas. Una actividad que viene tomando mucha fuerza entre los habitantes de la zona es la ganadería, hoy 10 comunidades se dedican a esta actividad en forma colectiva, a pesar del negativo impacto que esta genera sobre los suelos. 
Algunas de las comunidades se enfrentan nuevamente a una situación de desplazamiento, pero en sentido inverso al de sus antecesores, pues de la zona de várzea (llanura de inundación), han tenido que trasladarse a tierras altas (superficies onduladas); el cambio de unidad fisiográfica implica cualidades y características del paisaje que satisfacen de modo diferente las necesidades de los pobladores. Esto los ha llevado a poner en práctica sus habilidades adaptativas pues ha sido necesario el traslado y reconstrucción de su vivienda, la apertura de nuevas chagras que se rigen por otro ciclo de cultivo, situaciones como la presencia de la hormiga arriera o sauva (atta cephalotes), que no aparece en las zonas inundables y un mayor trabajo colectivo para reorganizar el asentamiento y dotarlo con la infraestructura de servicios que habían logrado alcanzar en el anterior.

\section{Estructura Social y Político- Administrativa}

Los cambios producidos a lo largo del tiempo han alterado la estructura social de los grupos como lo describe François Correa (1987), del grupo local ordenado por consanguinidad se pasa a unidades relacionadas por filiación y alianza matrimonial; de grupos locales de familias extensas, a casas de familias individuales reunidas en el espacio aldeano.

Inicialmente se asociaron alrededor de las Juntas de acción comunal. Este tipo de institución pretendía obtener y canalizar ayudas oficiales para satisfacer las necesidades de las gentes allí asentadas. Posteriormente la figura de la JAC cede lugar ante la institución del Cabildo y el Curaca; la asignación del cargo de curaca se hace por elección comunitaria para un período de un año y se tiene en cuenta la capacidad del aspirante para ejercer su función. Un curaca puede ser reelegido y revocado del cargo.

Cuando una nueva familia quiere venir a vivir en la comunidad, se hace una reunión general en la que se les pregunta la causa por la cual salieron de su anterior lugar de residencia y el motivo por el cual les conviene estar en el nuevo sitio; se hace una votación para decidir. Si la comunidad aprueba, se levanta un acta donde la familia recién llegada se compromete a participar en los trabajos de limpieza, en las reuniones y todo lo que el trabajo comunitario demande. El curaca les asigna un pedazo de terreno que puede ser de más o menos quince por veinte metros $(15 \times 20 \mathrm{~m})$. La nueva familia lo limpia para construir en él su vivienda. De igual manera se asigna un área de cultivo en la zona de chagras. El tamaño de esta depende de la capacidad que se tiene para trabajarla, igual sucede con el lote de la vivienda, se requiere mano de obra para mantenerlo; cuando cuentan con hijos o yernos que le permitan adecuar y cultivar en áreas mayores accederán a terrenos más grandes.

El trabajo comunitario tradicional a través de la minga tiene arraigo en muchas comunidades, para realizar actividades tales como la construcción de la casa

32 Elizabeth Riaño Umbarila 
unifamiliar y para abrir chagras. "El dueño de la minga hace el masato, consigue la comida, arroz, azúcar, si hay buena comida la gente viene", comenta Antero León y continúa: “....ahora preguntan cuando los invitas a una minga, ¿qué vas a hacer de comida? Vienen más si se ofrece gallina; cuando el dueño de la minga no da buena comida y masato los invitados no vuelven a aceptar la próxima invitación". La minga se ha ido transformando pero el espíritu se mantiene y fortalece los vínculos de solidaridad y unión. Sin embargo su sistema de organización socio-política y su mundo de representaciones ha sufrido permanentes procesos de transformación. En muchas de estas comunidades se destaca la presencia de iglesias católicas y evangélicas, con una notable influencia sobre los pobladores, imponiendo modelos de convivencia y orden social bajo la orientación de sus dogmas.

En el ámbito de las organizaciones distintas al cabildo, existen en los asentamientos ribereños grupos de madres comunitarias, grupos de jóvenes, defensa civil, agrupaciones de abuelos, órdenes religiosas como la Franciscana y asociación de artesanos. La mayoría se ha conformado por iniciativas externas y su duración se restringe a la vida del proyecto en torno al cual se crearon.

\section{Movilidad y desplazamiento}

Entre las causas de movilidad y desplazamiento de una familia se encuentra la búsqueda de un lugar donde sus hijos puedan acceder a educación, donde vivan sus familiares y donde encuentren personas con creencias religiosas compartidas. Los hombres y los jóvenes son los que se desplazan con mayor frecuencia entre asentamientos, la mujer permanece en casa siendo ella la más sedentaria; muchas de ellas no conocen las comunidades vecinas. Pero lo que más movilidad ha generado especialmente desde los asentamientos peruanos hacia los colombianos han sido los programas estatales, de tipo asistencial. Familias completas se han ubicado en caseríos de la ribera del Amazonas colombiano con la esperanza de que el gobierno los haga beneficiarios de cualquiera de sus programas, en particular el de mejoramiento de vivienda.

La mayoría de estos poblados han sido dotados con pequeños botes y motores que permiten a sus habitantes desplazarse hasta los centros urbanos de Leticia y Puerto Nariño para intercambiar sus productos o acceder a los servicios que el Estado ofrece.

\section{Conclusiones}

El análisis de las unidades fisiográficas existentes en la ribera del río Amazonas colombiano y la localización de los caseríos allí existentes permite corroborar la tendencia de ocupación presente en el área. Contrario a lo que ocurría en el siglo XVIII cuando los Ticuna intentaban establecerse en la zona de várzea que los Omagua ocupaban, los Ticuna del siglo 


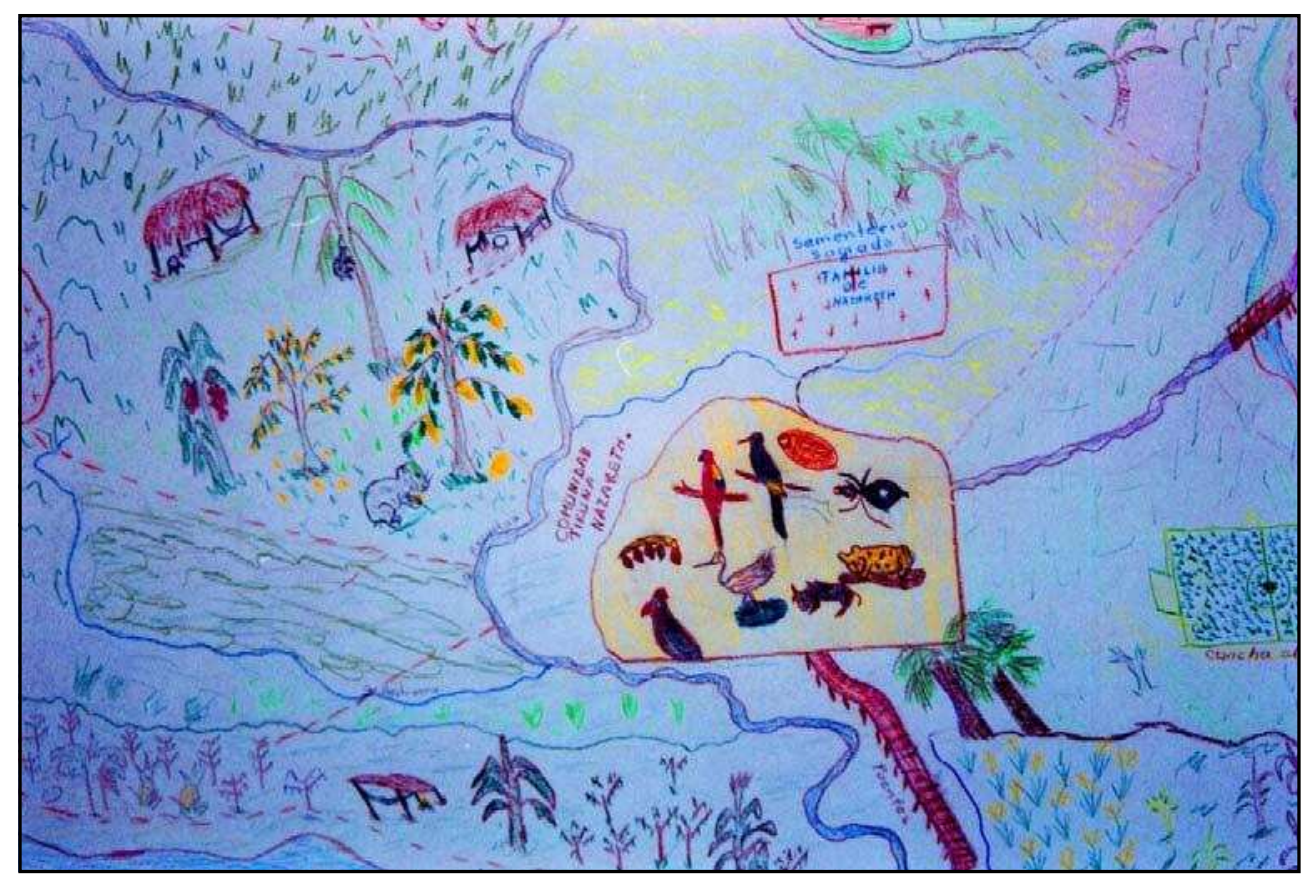

Figura No. 8. Nazareth, un asentamiento Ticuna.

Fuente: dibujo elaborada por jóvenes de Nazareth, junio de 2000.

XXI, avanzan en sentido sur norte. Es decir, de la zona de várzea o tierras bajas que algunos de estos caseríos ocupan actualmente, se están desplazando hacia las tierras altas.

Esta situación es común a lo largo del Amazonas, Wagley ya daba cuenta de ello en la década del cincuenta: "Verse-á toda a intensidade da vida da região amazónica trasladar-se do grande sistema fluvial para as das rodovías; ao invés das várzeas dos ríos ocupar-se-á terra firme. É nas várzeas que estãn as terras férteis, pois anualmente reciben o limo dos ríos, enquanto a terra firme é geralmente pobre para a agricultura" (Wagley 1988: 14).
La misma tendencia se presenta en la carretera Leticia-Tarapacá. Grupos de personas de diferente étnia, incluida gente no indígena, se han reunido para conformar nuevos caseríos con el fin de que el Estado colombiano atienda sus requerimientos a través de subsidios y otras políticas sociales que desde la década del setenta se vienen otorgando.

La presencia de caseríos en la ribera del Amazonas del lado colombiano se ha densificado. Las áreas intervenidas por las chagras o zonas de cultivo que hace unos años se encontraban a una distancia apreciable unas de otras hoy tienden a constituir una sola mancha. Véase el mapa No.3, en los sectores ribereños 
aledaños a los centros urbanos de Leticia y Puerto Nariño.

Estas exigencias ecológicas afectan a los indios bajo dos formas básicas tal, como lo mencionó Darcy Ribeiro. Primero como una competencia entre poblaciones que disputan recursos diferentes de un mismo territorio y culmina con la aniquilación intencional de los indios o la transformación de su hábitat en forma tan drástica que vuelve inoperante su antiguo sistema adaptativo, amenazándolos también por eso con su extinción.

La densidad de caseríos aumenta a medida que nos aproximamos a las áreas urbanas de Leticia y Puerto Nariño. En la zona de várzea hoy sólo se cuentan 7 asentamientos. Hace dos años eran diez $y$ es probable que en dos años haya menos de cinco pues algunos se encuentran en proceso de reubicación hacia tierras altas y otras planean hacerlo en corto plazo.

La realidad nos muestra que la zona de várzea ha dejado de ser el sitio preferido para el asentamiento de grandes caseríos con población numerosa. No obstante se mantiene como zona de cultivo muy apreciada por sus cualidades productivas. La dificultad para un mayor aprovechamiento de estas áreas está en las distancias que deben recorrer quienes las cultivan, ya que en muchos casos no se encuentran cerca del lugar en que tienen su vivienda. El análisis de los desplazamientos que la población Ticuna efectúa desde el caserío hasta el lugar donde tienen la chagra, determinó un promedio 20 minutos caminando, máximo una hora. Superior a este lapso de tiempo el mantenimiento de una chagra no es viable para estas familias.

Dentro de estas dos grandes unidades de paisaje fisiográfico se han implantado caseríos cuyas características tienen relación directa con el paisaje en que se encuentran. Tenemos agrupaciones de vivienda unifamiliares alineadas en forma paralela al caño o río en las zonas de várzea. El número de viviendas varía entre 10 y 60 albergando una o dos familias por casa. La zona se cultivo se encuentra allí mismo o a distancias menores a 30 minutos de camino.

En tierras altas la concentración de viviendas y pobladores es mayor. Se cuentan grandes caseríos como Arara que albergan hasta 130 viviendas con una población que oscila entre 300 y 600 personas. Las zonas de cultivo se encuentran a mayor distancia de recorrido, en promedio 30 minutos, pero en ocasiones puede alcanzar la hora, situación poco deseable dadas las dificultades para trasladar los productos que se cosechan.

La fachada de sus viviendas en ambos casos, se orienta hacia una "calle" que generalmente se convierte en un eje que las articula y es el principal espacio de encuentro comunitario; esta calle a su vez corre paralela al caño o río sobre el que se levanta el caserío. Se busca que las casas estén orientadas hacia el puerto. Lugar donde se desarrollan actividades cotidianas como el lavado de la ropa, los platos y el baño personal diario en cualquier momento del día. 
La generación de los actuales caseríos en la ribera del Amazonas tiene como constante tanto en tierras altas como en tierras bajas su desarrollo lineal, a partir del cual surgen nuevas líneas que se ubican de forma paralela o perpendicular a la primera. En tierras altas estas líneas van acomodándose a la topografía ondulada y cuando por este motivo no se da la orientación deseada de la vivienda, se buscan nuevos espacio como la cancha de fútbol hacia la cual también es deseable que mire la fachada principal de la casa.

En el centro de cada uno de los caseríos, el cual depende de la forma en que cada uno se haya desarrollado, se encuentran reunidas las principales infraestructuras provistas por el Estado. Son ellas el puesto de salud, los escenarios deportivos, la sede comunal, el jardín comunitario, la escuela o algunas de sus aulas en su primera fase, pues luego buscan un lugar mayor para su futuro crecimiento.

El tamaño de los caseríos se encuentra en relación directa con el número de familias residentes, aunque en tierras bajas son más estrechos debido a que los lugares altos aptos para el establecimiento de una vivienda son reducidos.

En este escenario se desarrolla la cotidianidad de los actuales pobladores quienes dependen principalmente de la producción de su chagra. El tamaño de la chagra varía entre 1 y 3 hectáreas en promedio, pero esto cambia si hay más brazos para trabajar y bocas que alimentar. La constante para todos es que se tiene la cantidad tierra para cultivar en función de la capacidad para trabajarla, no existe acumulación, pues la propiedad de la tierra es colectiva.

La organización social tradicional de los Ticuna se mantiene y se expresa espacialmente. Tal como afirma Oyuela y Vieco (1998), los grupos Ticuna pueden considerarse como unas sociedades de casas que han pasado de vivir en maloca a vivir en aldeas, donde persisten jerarquías de clanes o linajes atados a territorios específicos, en cumplimiento de la regla matrimonial entre clanes de fratrías opuestas.

Esta forma de organización social propia de los Ticuna, se evidencia espacialmente, tanto en el área de la cabecera como en las chagras o zonas de cultivo y en los desplazamientos que efectúan habitualmente hasta otros caseríos, haciéndolo con preferencia hacia aquellos con los cuales existen vínculos de familiaridad y/o consanguinidad. 


\section{Bibliografía}

Acosta, Luis Eduardo. La dimensión socio-económica de los sistemas de producción de la etnia Ticuna/Resguardo de Puerto Nariño, Trapecio Amazónico. Tesis de la Maestría en Desarrollo Sostenible de Sistemas Agrarios. Convenio Pontificia Universidad Javeriana, IMCA, CIPAV, Tercera Promoción. Febrero de 1999.

Botero, P. J., Jiménez, B. et. al. Estudio fisiográfico de la Orinoquia-Amazonia Colombiana. En: Revista Ciaf. Volumen 15, No. 1. Santafé de Bogotá D. C.: CIAF, 1997. pp. 7-63.

Correa, François. Indígenas Horticultores del Vaupés. En: Introducción a la Colombia Amerindia, p.p. 109-122. Bogotá. Instituto Colombiano de Antropología ICAN.1987.

FINEP/PPG-7 CGTT. Atlas das Terras Ticunas. Projeto Museu Nacional. Noviembre de 1998.

GEF/PNUD/UNOPS. Amazonia Peruana, Comunidades Indígenas Conocimientos y Tierras Tituladas. Atlas y Base de Datos. Lima.1997.

INSTITUTO GEOGRÁFICO AGUSTÍN CODAZZI. Zonificación Ambiental para el plan modelo Colombo-Brasilero (Eje Apaporis -Tabatinga: PAT). Santafe de Bogotá D. C.: Linotipia Bolívar, 1997.

Oyuela C., Augusto y Vieco A., Juan J. La Organización Social de los Ticuna del Trapecio Amazónico Colombiano: una aproximación cuantitativa. Ponencia presentada al Primer Encuentro de Investigadores e Indígenas en el Programa de Posgrado del Museo Nacional de la Universidad Federal de Río de Janeiro. 1998.

Riaño U., Elizabeth. Transformaciones de los asentamientos Ticuna en la ribera del río Amazonas colombiano. Tesis para optar el título Maestría en Geografía, énfasis en Ordenamiento Territorial, Convenio UPTC-IGAC, 2001.

Ribeiro, Darcy. Fronteras indígenas de la civilización. México: Siglo XXI Editores. $4^{\mathrm{a}}$. Edición. 1971.

Wagley, Charles. Uma comunidade amazónica, estudio del hombre en los trópicos. Traducción de Clotilde Da Silva Costa. Sao Paulo: Editora Itatiaia Universidad de Sao Paulo. 1988. 
